\title{
Analysis and Implementation of a Novel Ultra-High Step-Up DC/DC Converter
}

\author{
Sung-Pei Yang ${ }^{1}$, Shin-Ju Chen ${ }^{2}$, Chao-Ming Huang ${ }^{2}$, Zin-You Lin ${ }^{2}$ \\ ${ }^{1}$ Green Energy Technology Research Center/Kun Shan University \\ No.195, Kunda Rd., Yongkang Dist., Tainan City, Taiwan, R.O.C. \\ spyang@mail.ksu.edu.tw; sjchen@mail.ksu.edu.tw \\ ${ }^{2}$ Department of Electrical Engineering/Kun Shan University \\ No.195, Kunda Rd., Yongkang Dist., Tainan City, Taiwan, R.O.C. \\ h7440@ms21.hinet.net; ya12345177@gmail.com
}

\begin{abstract}
A novel ultra-high step-up power converter (UHSUPC) is proposed for wind input voltage range application in a renewable energy power systems. The proposed converter exhibits a much higher voltage conversion ratio without using the extremely large duty cycle. The voltage conversion ratio also has an extra factor of $1 /(1-\mathrm{D})$ compared with all the high step-up converters proposed in the literature. It means that the voltage gain will increase more than twice as the duty ratio D is operated more than 0.5 . The operating principle and state-state analysis are presented herein. Finally, a prototype of input voltage $40 \mathrm{~V}$, output voltage $400 \mathrm{~V}$, and output power $200 \mathrm{~W}$ prototype of the proposed converter is implemented to verify the theoretical analysis on the basis of the experimental results.
\end{abstract}

Keywords: ultra-high step-up, dc/dc converter, wide range

\section{Introduction}

Due to the growing population and the exhaustion of fossil fuel, many renewable energy sources, such as photovoltaic (PV), fuel cells [1-2], wind energy, hydraulic energy, biomass energy, geothermal energy, fuel cells, etc., have been widely used in electric grid system. A renewable energy distributed generation system is shown in Fig.1. The PV and fuel cells always generate a de voltage lower than $40 \mathrm{~V}$ [3] due to the safety and reliability considerations in the household applications, and thus a high-efficiency and high step-up dc-dc converter is applied to provide a high voltage dc bus of $380-400 \mathrm{~V}$, which is required for a single-phase $220 \mathrm{Vac}$ utility grid for the grid-connected dc/ac inverter.

Generally, an ideal conventional boost converter operating with an extreme large duty ratio can offer a high voltage gain. Unfortunately, the voltage gain of a conventional boost converter with the existing of the parasitic series resistor of a inductor [4] will decrease as the increasing of duty ratio. To overcome this drawback, many high step-up converter topologies are thus designed and presented in the literature [5-16]. As a result, an ultra-high step-up power converter (UHSUPC) is also proposed herein as shown in Fig.2 for wind input voltage range application in a renewable energy power system. The advantages and characteristics of the proposed UHSUPC are presented in the following:

(1) The proposed UHSUPC has a very high voltage conversion ratio without operating at extremely large duty cycle.

(2) The proposed UHSUPC can used for wide input voltage range application because the duty cycle does not have any limitations. The voltage gains of the proposed converter can reach 10 and 20 with $\mathrm{D}=0.36$ and $\mathrm{D}=0.56$, respectively.

(3) The power switches exhibit lower voltage stresses, which are all smaller than the high output voltage.

To ensure that the proposed converter exhibits the aforementioned features, the operating principle and steady-state analysis are given. A $200 \mathrm{~W} / 400 \mathrm{~V}$ output, $40 \mathrm{~V}$ input prototype is also built to test the performances herein.

\section{Operating Principle}

The proposed UHSUPC presented in Fig. 2 contains two switches $S_{1}, S_{2}$, which are driven complementarily with two small dead bands $T_{d}$ to avoid a short circuit across the DC voltage source and to achieve the zero-voltage switching (ZVS) at turn on operation for main switches. Some assumptions are made as follows before describing the operating principle of the proposed UHSUPC in a steady state. 


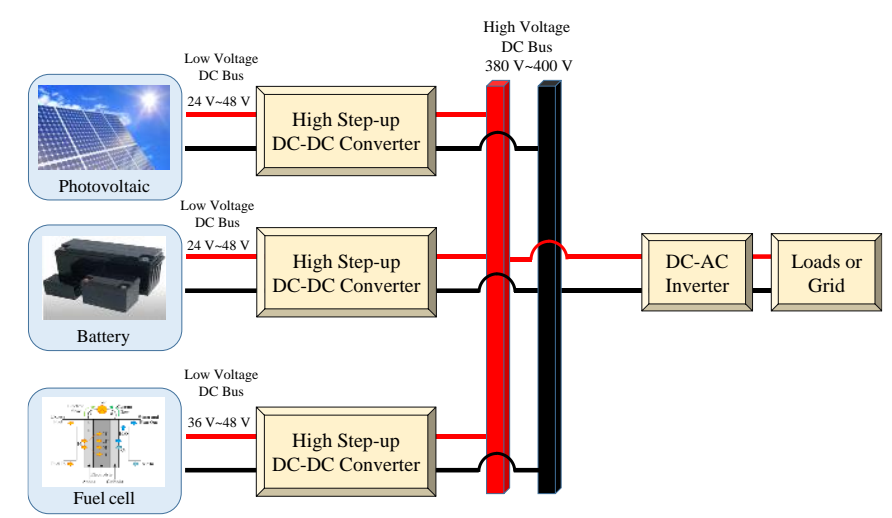

Fig. 1: Renewable energy distributed generation system.

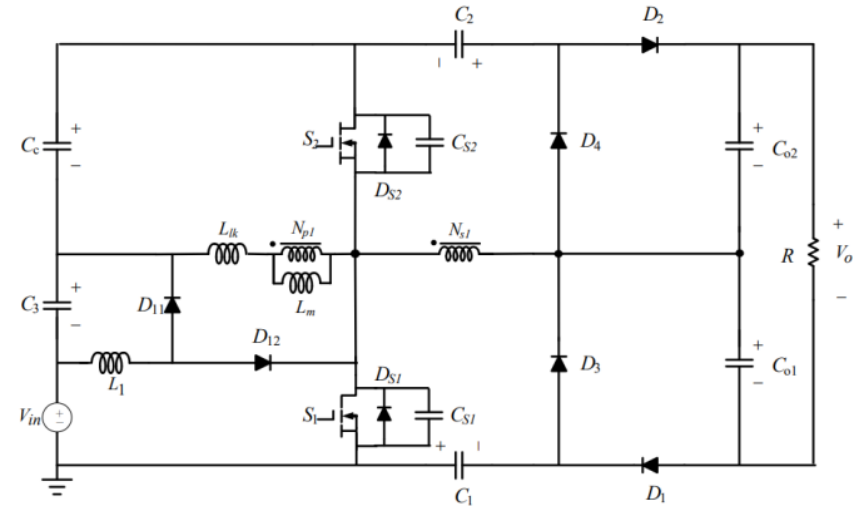

Fig. 2: Proposed UHSUPC.

(1) The proposed converter is operated in continuous conduction mode (CCM).

(2) All switches and diodes of the proposed UHSUPC are ideal. The switching time of the switches and the reverserecovery time of the diodes can be neglected.

(3) The boost capacitances $\left(C_{1}, C_{2}, C_{3}, C_{c}\right)$ and output capacitances $\left(C_{o 1}, C_{o 2}\right)$ are large enough so that their voltages are regarded as constant voltages $V_{c 1}, V_{c 2}, V_{c 3}, V_{C c}, V_{C o 1}, V_{C o 2}$ and $V_{o}$, respectively.

(4) Because the time intervals of the resonances and charge/discharge times of capacitors $C_{S 1}$ and $C_{S 2}$ are much smaller than the switching period $T_{S}$, the inductor currents are considered as constants during the turn-off and turn-on transitions.

(5) The turns ratio $n=N_{s 1} / N_{p 1}$ of the transformer is 1.

Based on the switching of the switches and diodes, the proposed converter operating over one switching period $T_{S}$ can be divided into ten linear modes described as follows. The equivalent circuit of each stage is presented in Fig. 3.

Mode $1\left[t_{0} \sim t_{1}\right]$ : [ $S_{1}$ :off $、 S_{2}$ :off $、 D_{1}$ :off $、 D_{2}$ :on $、 D_{3}$ : on $、 D_{4}$ : off $、 D_{11}$ : off $、 D_{12}$ : on]

The equivalent circuit of this mode is depicted in Fig. 3(a). This mode is started as the switch $S_{1}$ is turned off at $t=t_{0}$, and the switch $S_{2}$ is still off. The leakage inductor current $i_{L l k}$ continues to charge the capacitor $C_{S 1}$ and simultaneously to discharge the capacitor $C_{S 2}$ of the switch $S_{2}$. When the voltage $v_{d s 1}$ increases from zero to $V_{i n}+V_{c 3}$, the diode $D_{12}$ switches from on state to off state. The diode $D_{11}$ also becomes forward-biased simultaneously. At this time, this mode ends.

Mode $2\left[t_{1} \sim t_{2}\right]$ : [ $S_{1}$ :off $S_{2}$ :off $、 D_{1}$ :off $D_{2}$ :on $\backslash D_{3}$ : on $\backslash D_{4}$ : off $、 D_{11}$ : on $\backslash D_{12}$ : off]

The voltage $v_{d s 2}$ still drops in this mode. As it falls to zero, the body diode $D_{s 2}$ of the switch $S_{2}$ is turned on. After that, the switch $S_{2}$ can be thus turned on under ZVS operation, and this mode finishes. The equivalent circuit of this mode is shown in Fig. 3(b).

Mode $3\left[t_{2} \sim t_{3}\right]$ : [ $S_{1}$ :off $、 S_{2}$ :on $\backslash D_{1}$ :off $、 D_{2}$ :on $\backslash D_{3}$ : on $\backslash D_{4}$ : off $、 D_{11}$ : on $\backslash D_{12}$ : off $]$

Fig. 3(c) depicts the equivalent circuit of the mode 3. At this mode, the leakage inductor current $i_{L l k}$ starts to decrease because the negative voltage across the leakage inductor $L_{l k}$. When $i_{L l k}$ drops and is equal to the magnetizing inductor current $i_{L m}$, the diodes $D_{1}$ and $D_{4}$ become forward-biased, and the diodes $D_{2}$ and $D_{3}$ are switched from on to off. At this time, ode mode 3 also ends.

Mode 4[ $\left.t_{3} \sim t_{4}\right]$ : [ $S_{1}$ :off $、 . S_{2}$ :on $\backslash D_{1}$ :on $\backslash D_{2}$ :off $、 D_{3}$ : off $D_{4}$ : on $\backslash D_{11}$ : on $\backslash D_{12}$ : off] 
The leakage inductor current $i_{L l k}$ remains to decrease. As it drops to zero, this mode finishes. The equivalent circuit of this mode is demonstrated in Fig. 3(d).

Mode 5 [ $t_{4} \sim t_{5}$ ] : [ $S_{1}$ :off $S_{2}$ :on $\backslash D_{1}$ :on $\backslash D_{2}$ :off $、 D_{3}$ : off $、 D_{4}$ : on $\backslash D_{11}$ : on $\backslash D_{12}$ : off]

The leakage inductor current $i_{L l k}$ becomes negative in this mode. When the switch $S_{2}$ is turned off, this mode ends. The equivalent circuit of this mode is shown in Fig. 3(e).

Mode $6\left[t_{5} \sim t_{6}\right.$ ] : [ $S_{1}$ :off $、 S_{2}$ :off $、 D_{1}$ :on $、 D_{2}$ :off $、 D_{3}$ : off $、 D_{4}$ : on $、 D_{11}$ : on $D_{12}$ : off]

The equivalent circuit of this mode is depicted in Fig. 3(f). The leakage inductor current $i_{L l k}$ is negative and started to discharge the capacitor $C_{S 1}$ and simultaneously to charge the parasitic capacitor $C_{S 2}$. When the voltage $v_{d s 1}$ across the switch $S_{1}$ decreases to $V_{\text {in }}$, the diode $D_{12}$ and $D_{11}$ become forward-biased and reverse-biased, respectively. This mode is thus ended.

Mode $7\left[t_{6} \sim t_{7}\right.$ ] : [ $S_{1}$ :off $S_{2}$ :off $D_{1}$ :on $、 D_{2}$ :off $、 D_{3}$ : off $、 D_{4}$ : on $、 D_{11}$ : off $、 D_{12}$ : on]

The voltage $v_{d s 1}$ still drops in this mode. However, the current $i_{L 1}$ will flow through the capacitor $C_{S 1}$, the voltage $v_{d s 1}$ may be charged and cannot continue to drop. It means that the switch $S_{1}$ can just be turned on under quasi zero voltage switching (QZVS), and this mode finishes. The equivalent circuit of this mode is shown in Fig. 3(g).

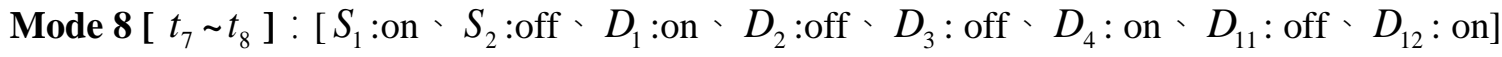

Fig. 3(h) depicts the equivalent circuit of this mode. At this mode, the leakage inductor current $i_{L l k}$ starts to increase because the positive voltage across to the leakage inductor $L_{l k}$. The leakage inductor current $i_{L l k}$ remains to increase from negative value. As it increases to zero, the mode finishes.

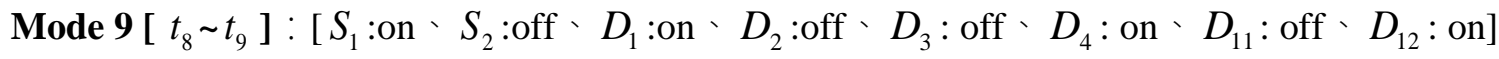

The leakage inductor current $i_{L l k}$ continues to increase from zero. When $i_{L l k}$ increases and is equal to the magnetizing inductor current $i_{L m}$, the diodes $D_{1}$ and $D_{4}$ become reverse-biased, and the diodes $D_{2}$ and $D_{3}$ are switched from off to on. This mode ends. The equivalent circuit of this mode is demonstrated in Fig. 3(i).

Mode 10 [ $t_{9} \sim t_{10}$ ] : [ $S_{1}$ :on $、 S_{2}$ :off $D_{1}$ :off $、 D_{2}$ :on $、 D_{3}$ : on $、 D_{4}$ : off $、 D_{11}$ : off $、 D_{12}$ : on]

The leakage inductor current $i_{L l k}$ still rises in this mode. When the switch $S_{1}$ is turned off, this mode ends and next ten modes for a switching period repeat again. The equivalent circuit of this mode is shown in Fig. 3(j).

As a result, the key waveforms over one switching period are schematically depicted in Fig. 4 based on the circuit analysis of the ten modes.

\section{Converter Performance Analysis}

\section{A. Voltage Gain Expression}

Based on the voltage-second balance principle of the inductor $L_{1}$ and magnetizing inductor $L_{\mathrm{m}}$, it yields

$$
V_{c 3}=V_{i n} \times \frac{D}{(1-D)}
$$

and

$$
V_{C c}=V_{i n} \times \frac{D}{(1-D)^{2}}
$$


where $D$ is the duty cycle of the power switch of $S_{1}$. On the basis of the operating principle, the voltages across the output capacitors can be derived as follows. According to the equivalent circuits in mode 10 and mode 4 shown in Fig. 3(j) and Fig. 3(d), respectively, and Kirchhoff's Voltage Law (KVL), one gets

$$
\begin{gathered}
V_{c 1}=n\left(V_{c 3}+V_{i n}\right) \\
V_{C o 2}=V_{c 1}+V_{c 2}+V_{c 3}+V_{C c}+V_{i n}
\end{gathered}
$$

and

$$
\begin{gathered}
V_{c 2}=n \times V_{C c} \\
V_{C o 1}=V_{c 1}+V_{c 2}+V_{c 3}+V_{C c}+V_{i n}
\end{gathered}
$$

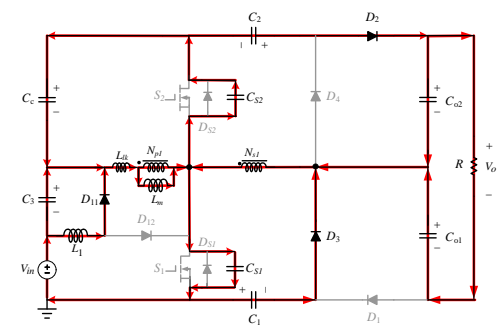

(a) Mode $1\left[t_{0} \sim t_{l}\right]$

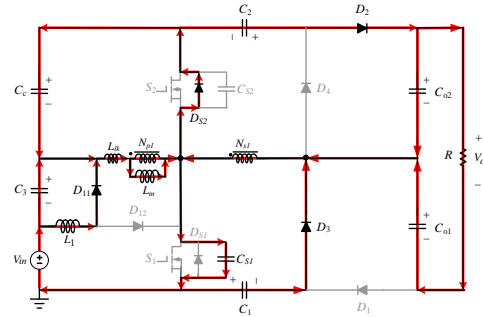

(b) Mode $2\left[t_{1} \sim t_{2}\right]$

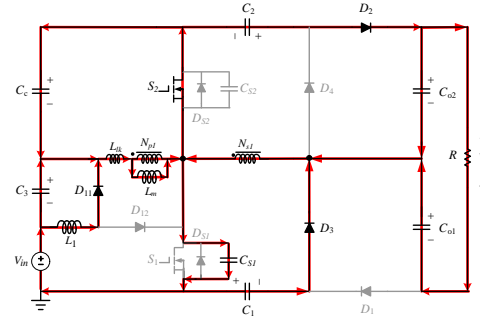

(c) Mode $3\left[t_{2} \sim t_{3}\right]$

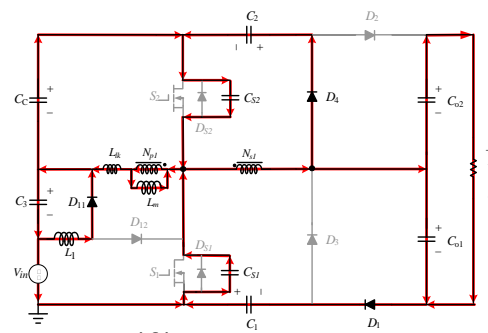

(f) Mode $6\left[t_{5} \sim t_{6}\right]$

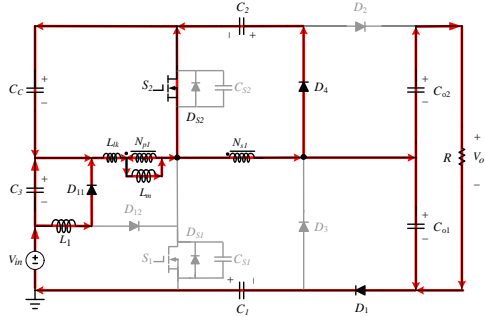

(d) Mode $4\left[t_{3} \sim t_{4}\right]$

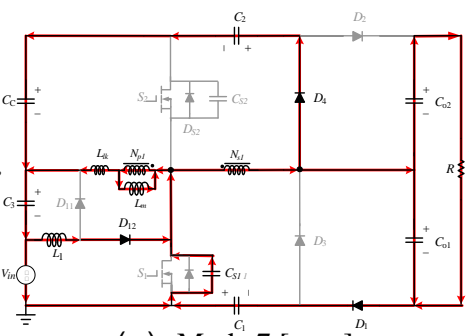

(g) Mode $7\left[t_{6} \sim t_{7}\right]^{D_{1}}$

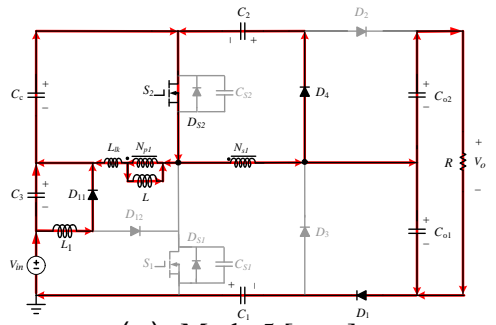

(e) Mode $5\left[t_{4} \sim t_{5}\right]^{C_{1}}$

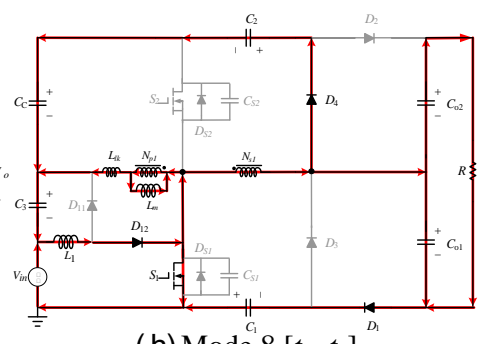

(h) Mode $8\left[t_{7} \sim t_{8}\right]$

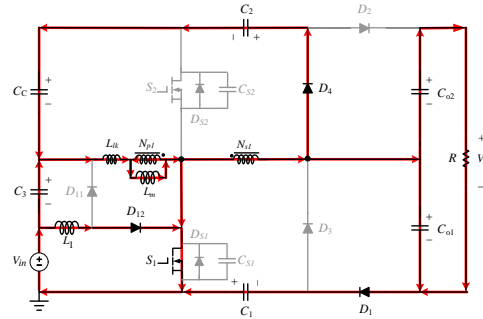

(i) Mode $9\left[t_{8} \sim t_{9}\right]$

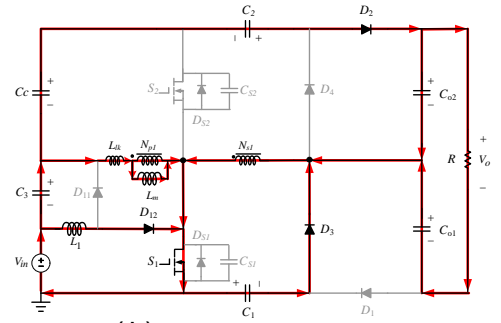

(j) Mode $10\left[t_{9} \sim t_{10}\right]$

Fig. 3: Equivalent circuits for each mode of proposed UHSUPC.

Substituting Eqs. (1)-(3) and Eq. (5) into Eq. (4) and Eq. (6), thus we have

$$
V_{C o 1}=V_{C o 2}=V_{i n} \times \frac{(1+n)}{(1-D)^{2}}
$$


Therefore, the output voltage of the proposed UHSUPC can be determined from Eq. (7) as

$$
V_{o}=V_{C o 1}+V_{C o 2}=\frac{2(n+1)}{(1-D)^{2}} V_{i n}
$$

As a result, the voltage conversion ratio is derived as

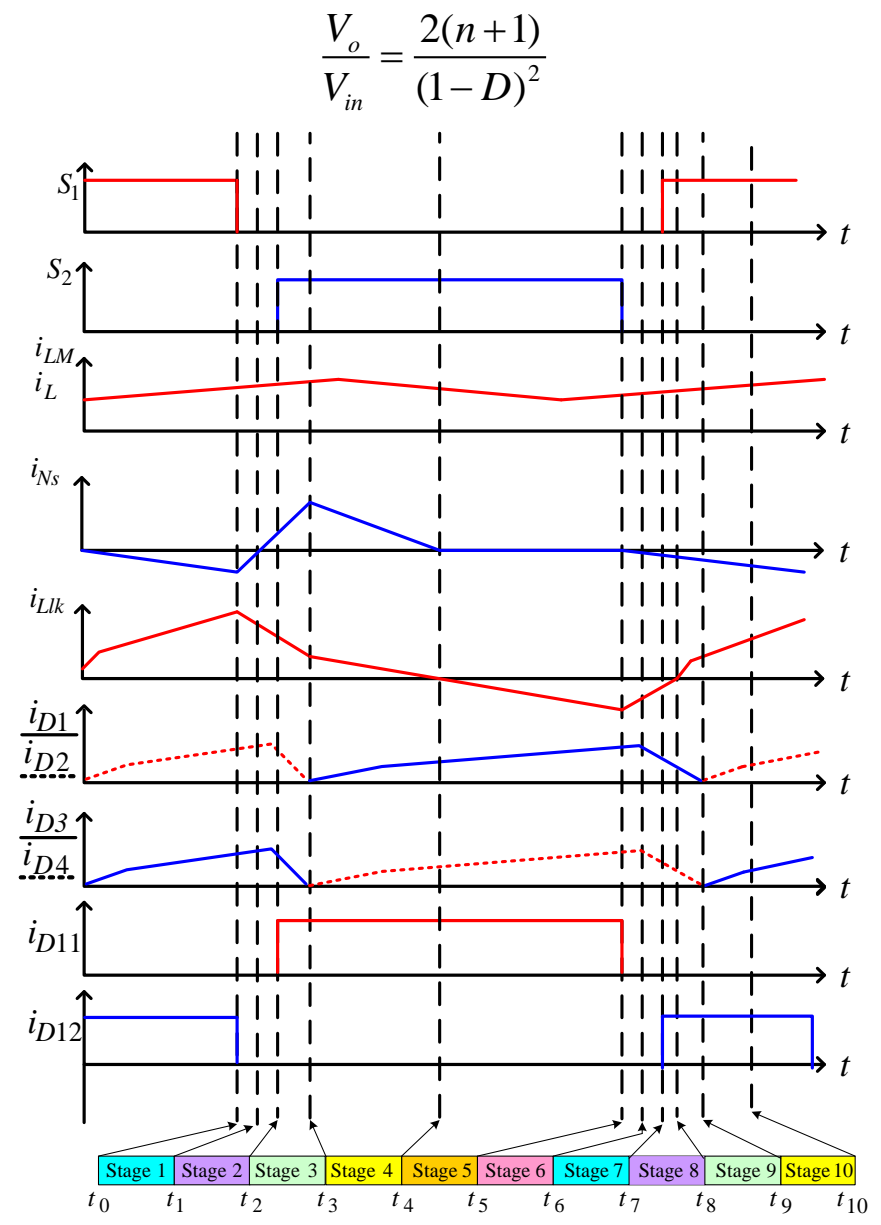

Fig. 4: Key waveforms of proposed UHSUPC.

According to Eq. (9), the voltage conversion ratio curves related to turns ratio $n(\mathrm{n}=1,2,3)$ and duty ratio $D$ are derived and shown in Fig. 5. It reveals from Fig. 5 that the duty ratio 0.36 is applied to get the voltage conversion ratio 10 at a turns ratio $n=1$. It means that the proposed UHSUPC can achieve high step-up voltage conversion ratio without operating in an extreme duty cycle. Moreover, when the duty ratio is 0.56 , it can also derive an ultra-high voltage gain of 20. 


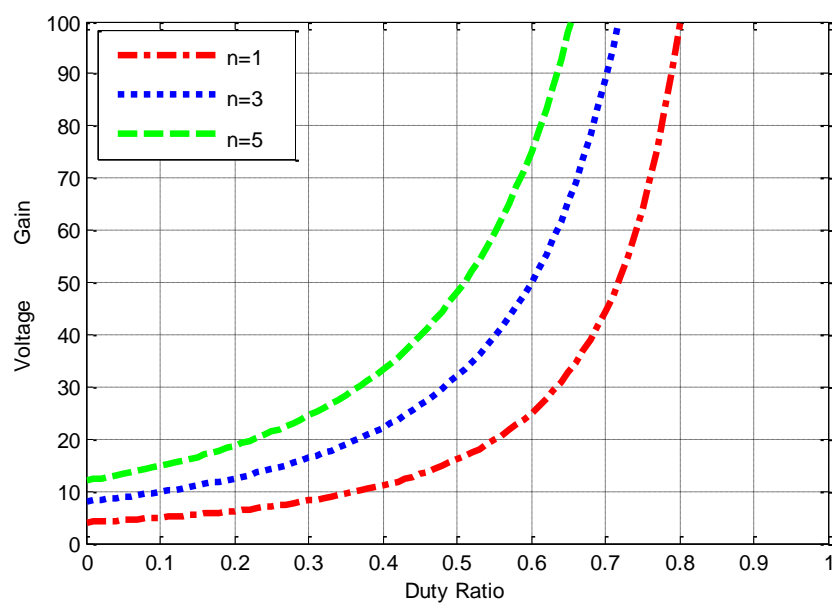

Fig. 5: Voltage conversion ratio curve versus duty cycle with various turns ratio.

\section{B. Voltages across Power Switches and Capacitors}

According to the operating principle, the voltage stresses across the power switches and diodes are given by

$$
\begin{gathered}
v_{D S\left(S_{1}\right)}=v_{D S\left(S_{2}\right)}=\frac{V_{\text {in }}}{(1-D)^{2}}=\frac{1}{2(1+n)} V_{O} \\
v_{D 11(\max )}=v_{c 3}=V_{i n} \times \frac{D}{(1-D)}=\frac{D(1-D)}{2(1+n)} V_{O} \\
v_{D 12(\max )}=v_{C c}=V_{i n} \times \frac{D}{(1-D)^{2}}=\frac{D}{2(1+n)} V_{O} \\
v_{\mathrm{D} 1(\max )}=v_{\mathrm{D} 2(\max )}=v_{\mathrm{D} 3(\max )}=v_{\mathrm{D} 4(\max )}=\frac{V_{\mathrm{O}}}{2}
\end{gathered}
$$

It reveals from Eqs. (10)-(13) that the voltage stresses across the power devices of the proposed UHSUPC are all lower than the output voltage. Therefore, it is compared with the conventional boost converter that the proposed UHSUPC has the less conduction losses and cost because the low-voltage-rated MOSFETs with low $R_{d s(\text { on) }}$ can be employed.

\section{Experimental Results}

A $200 \mathrm{~W}$ prototype of proposed UHSUPC with input voltage of $40 \mathrm{~V}$, output voltage of $400 \mathrm{~V}$ and switching frequency of $100 \mathrm{kHz}$ is built to validate the theoretical results. The power specifications and component parameters are listed in Table I. Fig. 6 shows that $V_{i n}=40 \mathrm{~V}$ and $V_{o}=400 \mathrm{~V}$ are derived as the duty ratio $D$ is about 0.4 , which is approximated to the theoretical result of 0.36. It reveals that the high voltage gain is obtained without operating at an extremely large duty ratio. Fig. 7 depicts the waveforms of gating signals and the drain-source voltages of power switches. The voltage stresses of $102 \mathrm{~V}$ across the power switches are about one-fourth of the output voltage of $400 \mathrm{~V}$.

Table 1: POWER SPECIFICATIONS AND COMPONENT PARAMETERS

\begin{tabular}{|c||c||c||c||}
\hline$V_{\text {in }}$ & $40 \mathrm{~V}$ & $V_{o}$ & $400 \mathrm{~V}$ \\
\hline$P_{o}$ & $200 \mathrm{~W}$ & $f_{S}$ & $100 \mathrm{kHz}$ \\
\hline \hline$n$ & 1 & $L_{m}$ & $200 \mu \mathrm{H}$ \\
\hline
\end{tabular}




\begin{tabular}{|c|c|c|c|}
\hline$C_{1}, C_{2}$ & $10 \mu \mathrm{F}$ & $L_{1}$ & $500 \mu \mathrm{H}$ \\
\hline \hline$C_{c} 、 C_{o 1}, C_{o 2}$ & $47 \mu \mathrm{F}$ & $C_{3}$ & $220 \mu \mathrm{F}$ \\
\hline
\end{tabular}

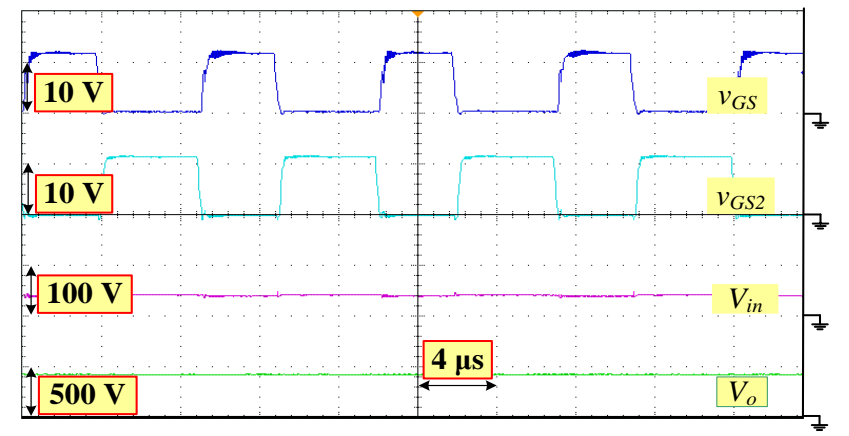

Fig. 6: Gating signals of switches and the input/output voltages.

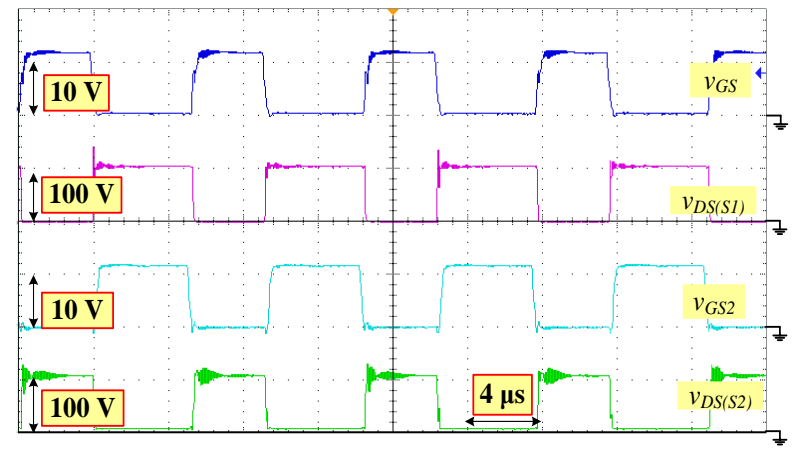

Fig. 7: Gating signals and the drain-source voltages of switches.

Fig. 8 shows that the experimental results of $V_{\mathrm{c} 3}=24.6 \mathrm{~V}$ and $V_{C c}=45.2 \mathrm{~V}$, which are approximate to the theoretic results of $V_{\mathrm{c} 3}=26.67 \mathrm{~V}$ and $V_{\mathrm{Cc}}=44.4 \mathrm{~V}$ from Eqs. (1)-(2) with $D=0.4$. Fig. 9 depicts that the experimental results of $V_{\mathrm{c} 1}=49.2 \mathrm{~V}$ and $V_{\mathrm{c} 2}=42.7 \mathrm{~V}$, which are also approximate to the theoretic results of $V_{\mathrm{c} 1}=44.6 \mathrm{~V}$ and $V_{\mathrm{c} 2}=44.4 \mathrm{~V}$ from Eq. (4) and Eq. (5), respectively, with $D=0.4$.

The voltage waveforms on the diodes $\left(D_{1}, D_{2}, D_{3}\right.$ and $\left.D_{4}\right)$ and $\left(D_{11}\right.$ and $\left.D_{12}\right)$ are shown in Fig. 10 and Fig. 11. It reveals form Fig. 10 that all the voltages across diodes are close to $V_{\mathrm{o}} / 2$, which is $200 \mathrm{~V}$. Based on Fig. 10, we get that the voltage stresses of diodes $\left(D_{11}\right.$ and $\left.D_{12}\right)$ are about $V_{\mathrm{o}} / 4$, which is $100 \mathrm{~V}$.

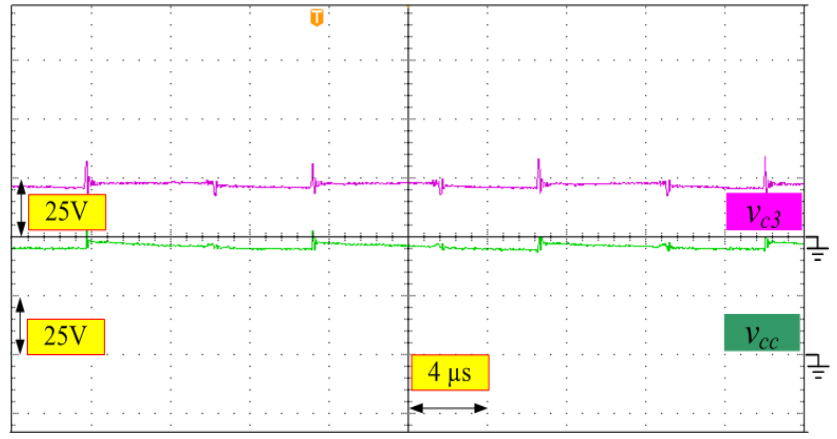

Fig. 8: Capacitor voltages of capacitors $C_{3}$ and $C_{\mathrm{c}}$.

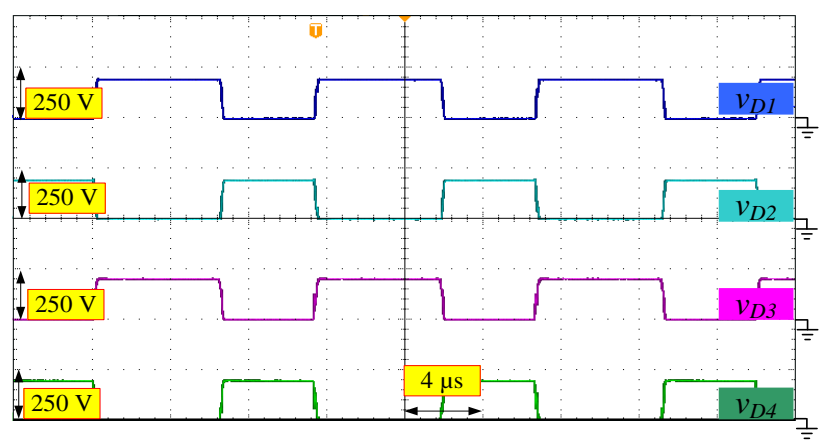

Fig. 10: Voltages of diodes $D_{1}, D_{2}, D_{3}$ and $D_{4}$.

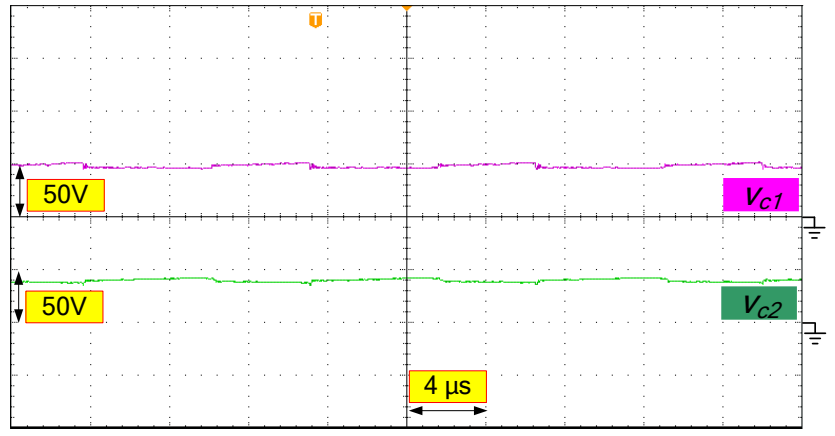

Fig. 9: Capacitor voltages of capacitors $C_{1}$ and $C_{2}$.

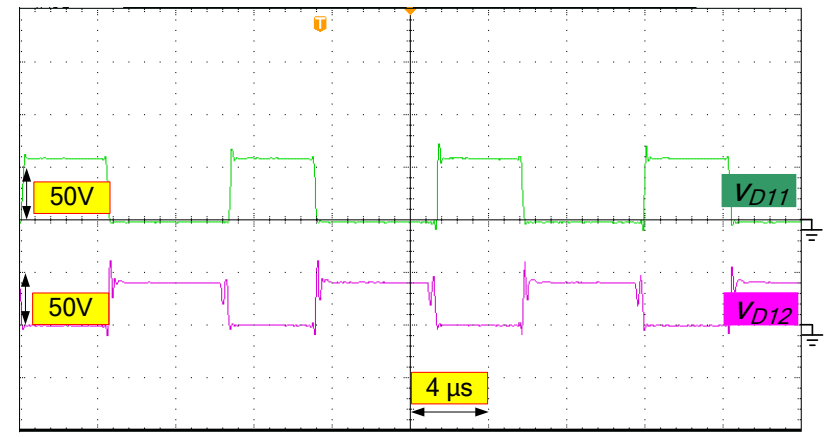

Fig. 11: Voltages of diodes $D_{11}$ and $D_{12}$. 


\section{Conclusions}

For a high step-up conversion application, a novel ultra-high step-up power converter (UHSUPC) is proposed in this paper. The operating duty ratio does not have the limitation, thus the proposed converter can be used for wide input voltage range applications. Based on the operating principle and steady-state analysis herein, it shows that the voltage gains of the proposed converter can reach 10 and 20 with $D=0.36$ and $D=0.56$, respectively. Moreover, the voltage stresses across all the power devices are much lower than output voltage. Finally, a $200 \mathrm{~W}$ prototype is implemented, and the theoretical results of the proposed UHSUPC are thus validated by experimental results.

\section{References}

[1] J. M. Carrasco, L. G. Franquelo, J. T. Bialasiewicz, E. Galvan, R. C. P.Guisado, M. A. M. Prats, J. I. Leon, and N. Moreno-Alfonso, "Power-electronic systems for the grid integration of renewable energy sources: A survey," IEEE Trans. Ind. Electron., vol. 53, no. 4, pp. 1002-1016, 2006.

[2] B. Yang, W. Li, Y. Zhao, and X. He, "Design and analysis of a grid connected PV power system," IEEE Trans. Power Electron., vol. 25, no. 4, pp. 992-1000, 2010.

[3] A. Ajami, H. Ardi, and A. Farakhor, "A novel high step-up DC-DC converter based on integrating coupled inductor and switched-capacitor techniques for renewable energy applications," IEEE Trans. Power Electron., vol. 30, no. 8, pp. 4255-4263, 2015.

[4] F. L. Tofoli, D. C. Pereira, W. J. Paula, and D. S. O. Junior, "Survey on non-isolated high-voltage step-up DC-DC topologies based on the boost converter," IET Power Electron., vol. 8, no. 8, pp. 2044-2057, 2015.

[5] C. L. Shen, P. C. Chiu, and Y. C. Lee, "Novel interleaved converter with extra-high voltage gain to process lowvoltage renewable-energy generation," Energies, vol. 9, pp. 871-882, 2016.

[6] K. C. Tseng, and C. C. Huang, "High step-up high-efficiency interleaved converter with voltage multiplier module for renewable energy system," IEEE Trans. Ind. Electron., vol. 61, no. 3, pp. 1311-1319, 2014.

[7] C. T. Pan, C. F. Chuang, and C. C. Chu, "A Novel transformer-less adaptable voltage quadrupler dc converter with low switch voltage stress," IEEE Trans. Power Electron., vol. 29, pp. 4787-4796, 2014.

[8] Y. S. Wong, J. F. Chen, K. B. Liu, and Y. P. Hsieh, "A novel high step-up DC-DC converter with coupled inductor and switched clamp capacitor techniques for photovoltaic systems," Energies, vol. 10, pp. 378-394, 2017.

[9] K. C. Tseng, C. T. Chen, and C. A. Cheng, "A high-efficiency high step-up interleaved converter with a voltage multiplier for electric vehicle power management applications," Journal of Power Electron., vol. 16, no. 2, pp. 414-424, 2016.

[10] H. Liu, J. Ai, and F. Li, "A novel high step-up converter with a switched-coupled-inductor-capacitor structure for sustainable energy systems," Journal of Power Electron., vol. 16, no. 2, pp. 436-4446, 2016.

[11] Y. P. Siwakoti and F. Blaabjerg, "Single switch nonisolated ultra-step-up DC-DC converter with an integrated coupled inductor for high boost applications," IEEE Trans. Power Electron., vol. 32, no. 11, pp. 8544-8558, 2017.

[12] S. W. Lee and H. L. Do, "Zero-ripple input-current high-step-up Boost-SEPIC DC-DC converter with reduced switch-voltage stress," IEEE Trans. Power Electron., vol. 32, no. 8, pp. 6170-6177, 2017.

[13] B. Akhlaghi, N. Molavi, M. Fekri and H. Farzanehfard, "A novel high step-up DC-DC converter based on integrating coupled inductor and switched-capacitor techniques for renewable energy applications," IEEE Trans. Ind. Electron., vol. 65 , no. 1, pp. 291-299, 2018.

[14] R. Moradpour, H. Ardi and A. Tavakoli,, "Design and implementation of a new SEPIC-Based high step-up DC/DC converter for renewable energy applications," IEEE Trans. Ind. Electron., vol. 65, no. 2, pp. 1290-1297, 2018.

[15] A. Alzahrani, M. Ferdowsi, and P. Shamsi, "High-voltage-gain dc-dc step-up converter with bifold dickson voltage multiplier cells," IEEE Trans. Power Electron., vol. 34, no. 10, pp. 9732-9742, 2019.

[16] T. Zeng, Z. Wu, and L. He, "An interleaved soft switching high step-up converter with low input current ripple and high efficiency," IEEE Access, vol. 7, pp. 93580-93593, 2019. 